\title{
Diagnostic accuracy of pre-operative imaging findings in presumed clinical T1a renal cell carcinomas
}

\author{
KAZUFUMI NAKASHIMA ${ }^{1}$, YASUHIDE KITAGAWA ${ }^{1}$, KOUJI IZUMI ${ }^{1}$, ATSUSHI MIZOKAMI ${ }^{1}$, \\ TOSHIFUMI GABATA $^{2}$ and MIKIO NAMIKI ${ }^{1}$ \\ Departments of ${ }^{1}$ Integrative Cancer Therapy and Urology, and ${ }^{2}$ Radiology, \\ Kanazawa University Graduate School of Medical Science, Kanazawa, Ishikawa 920-8640, Japan
}

Received November 19, 2014; Accepted October 9, 2015

DOI: $10.3892 / \mathrm{ol} .2016 .4330$

\begin{abstract}
Despite the development of recent imaging modalities, certain pathological misdiagnoses remain for surgical specimens of presumed small renal cell carcinomas (RCCs). In the present study, a retrospective analysis of benign pathological lesions diagnosed as small RCC prior to surgery was performed. In total, the cases of 196 sporadic renal tumors that was surgically treated as clinical T1a RCCs were reviewed, and the accuracy of the pathological diagnoses was calculated. The pre-operative findings for benign pathological lesions was investigated, and the lesions were observed in 13 (6.63\%) of the 196 tumors. Pre-operative computed tomography images were obtained in all cases, and magnetic resonance images were available in 10 cases. The diagnostic accuracy of imaging modalities was significantly lower in the tumors with a diameter of $\leq 20 \mathrm{~mm}$. In all cases, the possible pathological diagnosis of RCC could not be excluded even by retrospective imaging analysis. Several benign pathological lesions were found in small renal masses presumed to be clinical T1a RCC. In conclusion, there may be limitations to the pre-operative imaging for certain types of small renal mass.
\end{abstract}

\section{Introduction}

In 2012, an estimated 338,000 novel cases of renal cancer were diagnosed worldwide (1). Clinical stage I disease accounts for $\sim 70 \%$ of newly identified renal tumors, the majority of which are small renal tumors of $\leq 4 \mathrm{~cm}$ diameter (T1a) $(2,3)$. A 5-year cancer-specific survival rate of $>95 \%$ has been demonstrated in clinical T1a disease following the administration of optimal treatments, including partial nephrectomy and radiofrequency

Correspondence to: Dr Yasuhide Kitagawa, Department of Integrative Cancer Therapy and Urology, Kanazawa University Graduate School of Medical Science, 13-1 Takara-machi, Kanazawa, Ishikawa 920-8640, Japan

E-mail: yasukita@med.kanazawa-u.ac.jp

Key words: small renal mass, clinical T1a renal cell carcinoma, benign pathology, pre-operative imaging ablation (4). The detection rate of renal tumors has increased due to the widespread use of imaging techniques, such as ultrasonography and computed tomography (CT). These imaging modalities enable the clinical diagnosis of almost all tumors pre-operatively. However, the incidence rate of benign lesions among clinical cases of presumed T1a renal cell carcinoma (RCC) in surgical specimens ranges from $7.1-19.5 \%$ (5-8). It is difficult to distinguish benign small renal lesions, including oncocytoma, angiomyolipoma (AML) and compromised cysts, from clinical T1a RCC by routine examinations prior to surgery (5-8).

CT remains the most widely used and single most effective modality for the staging of RCC (9). However, there has been a recent trend toward the performance of detailed pre-operative examinations using magnetic resonance (MR) imaging for small renal masses. The small amounts of fat in renal masses may be detected in MR imaging, and small cystic renal masses may be better categorized in MR imaging compared with CT (10-13). Combined pre-operative imaging analysis for small renal masses may lead to a correct pathological diagnosis. However, there have been few previous studies regarding the correspondence rate of the diagnosis between clinical pre-operative imaging and pathological findings.

The present study was performed to determine the incidence of benign pathological findings for small renal masses diagnosed as clinical Tla RCC prior to surgery, and to retrospectively analyze the utility of pre-operative CT and MR imaging of benign pathological lesions.

\section{Patients and methods}

Patients and treatment. Between January 1998 and December 2011, 196 cases of sporadic renal tumors, with a diameter of $\leq 4 \mathrm{~cm}$ determined on $\mathrm{CT}$ and/or MR imaging for pre-operative evaluation, were surgically treated as clinical T1a RCC at the Department of Integrative Cancer Therapy and Urology, Kanazawa University Graduate School of Medical Science, Kanazawa, Japan. Cases with bilateral and/or multiple lesions or von Hippel-Lindau disease were excluded from this study.

Pre-operative evaluation. Pre-operative evaluations, including blood a test, chest and abdominal CT with dynamic scan, 
and bone scintigraphy, were performed. MR imaging was performed in selected patients. CT and MR imaging findings were reviewed by two radiologists, and urologists made a diagnosis based on their reports and clinical findings.

Treatment and post-operative analysis. All patients underwent radical nephrectomy (RN) or nephron-sparing surgery (NSS). Pathological stage, Fuhrman nuclear grade (14) and histological subtype were assessed according to the Heidelberg classification (15) and the 2002 American Joint Committee on Cancer version of the tumor-node-metastasis staging system (16). Pathological diagnosis was made by various immunohistological procedures, including cytokeratin AE1/AE3, 7 and CD10 staining, for the selected cases in which it was difficult to distinguish between RCC and benign lesions based on pathology.

The patients' medical records were reviewed, and the rate of correspondence with the pre-operative diagnosis was calculated. The pre-operative imaging results for benign small renal lesions were retrospectively examined on pathological reports.

In our previous study, of the 196 eligible cases in the present study, the clinical outcomes of 105 cases with cT1aN0M0 renal cell carcinoma were examined, and it was demonstrated that disease recurrence occurred in 6 patients (5.7\%) during a mean postoperative follow-up period of 41.7 months (17).

In this analysis, the principles of the Helsinki Declaration were followed, and all patients provided written informed consent with guarantees of confidentiality. The present study was approved by the ethics committee of Kanazawa University (Kanazawa, Japan).

Statistical analysis. Statistical analyses were performed using commercially available software (GraphPad Prism; GraphPad Software, Inc., La Jolla, CA, USA). Comparisons between two groups were performed by Student's unpaired t-test and Fisher's exact test. In all analyses, $\mathrm{P}<0.05$ was considered to indicate a statistically significant difference.

\section{Results}

Clinical characteristics of pre-operatively diagnosed cTla renal cell carcinoma patients. A pre-operative diagnosis of clinical T1a RCC was made in 196 cases. Of these 196 tumors, RCC was detected in 183 cases (93.37\%) and benign pathological lesions in 13 cases (6.63\%) (Table I). The benign cases were pathologically diagnosed as AML $(\mathrm{n}=4 ; 2.04 \%)$, oncocytoma $(n=3 ; 1.53 \%)$, renal cysts $(n=4 ; 2.04 \%)$, xanthogranulomatous pyelonephritis $(n=1 ; 0.51 \%)$ and leiomyoma $(n=1 ; 0.51 \%)$. There were no significant associations between the age of the patient and the pathological findings. The benign pathological lesions were found in 11 female and 2 male patients, and the correlation between gender and benign pathological findings was statistically significant $(\mathrm{P}<0.05)$. The mean diameter of the benign pathological lesions was $19.5 \mathrm{~mm}$ (range, 12-28 cm), and the incidences of benign pathological lesions with a diameter of $\leq 20 \mathrm{~mm}$ and with tumors $>20 \mathrm{~mm}$ in diameter were 12.7 and $3.2 \%$, respectively. The tumor diameters of the benign lesions were significantly smaller than those of RCC. In terms
Table I. Patient characteristics.

\begin{tabular}{lrcr}
\hline Variables & RCC & Benign & P-value \\
\hline Total patients, $\mathrm{n}$ & 183 & 13 & \\
Mean age, years & 62.8 & 60.7 & $0.5631^{\mathrm{a}}$ \\
Gender, $\mathrm{n}$ & & & \\
$\quad$ Male & 129 & 2 & $0.0002^{\mathrm{b}}$ \\
$\quad$ Female & 54 & 11 & \\
Diameter of tumor, mm & & & \\
$\quad$ Mean & 24.7 & 19.5 & $0.0319^{\mathrm{a}}$ \\
$\quad 20, \mathrm{n}$ & 62 & 9 & $0.0236^{\mathrm{b}}$ \\
$>20, \mathrm{n}$ & 121 & 4 & \\
Surgery, n & & & \\
$\quad$ RN & 105 & 2 & $0.0080^{\mathrm{b}}$ \\
$\quad$ NSS & 78 & 11 & \\
\hline
\end{tabular}

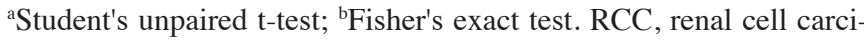
noma; RN, radical nephrectomy; NSS, nephron-sparing surgery.

of surgical procedure, the rate of NSS was significantly higher than $\mathrm{RN}$ in the benign pathological lesions.

Diagnostic accuracy of pre-operative imaging findings. Table II shows the accuracy of pre-operative CT and MR imaging findings according to tumor diameter. All patients underwent CT scans, and $152(77.55 \%)$ of the total of 196 patients underwent MR imaging prior to surgery. CT and MR imaging findings were obtained for all 9 of the benign pathological lesions that were $\leq 20 \mathrm{~mm}$ in diameter; however, MR imaging was performed in only 1 case with tumors $>20 \mathrm{~mm}$ in diameter. The diagnostic accuracies of pre-operative $\mathrm{CT}$ and MR imaging findings of the renal masses $\leq 20 \mathrm{~mm}$ in diameter were significantly lower than those of masses $>20 \mathrm{~mm}$ in diameter.

Pre-operative imaging findings of benign renal masses. In the retrospective $\mathrm{CT}$ and MR imaging analysis, none of the 9 benign pathological lesions with a diameter of $\leq 20 \mathrm{~mm}$ could be distinguished from RCC. A total of 3 cases of AML had no identifiable macroscopic fat on pre-operative CT and MR imaging. Another 3 cases of renal cysts classified as category III according to the Bosniak renal cyst classification system $(12,18)$ showed enhancement characteristics of septa on contrast-enhanced CT and MR imaging. In 2 cases of oncocytoma and 1 case of leiomyoma, benign pathological lesions could not be distinguished from RCC by retrospective image analysis.

With regard to the 4 benign renal masses with a diameter of $>20 \mathrm{~mm}, 1$ case that underwent pre-operative MR imaging was AML. Small areas of low attenuation in the renal mass were found on CT and MR imaging; however, the mass showed marked contrast enhancement in the arterial phase and washout of contrast medium in the late phase suggesting RCC (Fig. 1). The other three cases without pre-operative MR imaging were a hemorrhagic cyst, oncocytoma and xanthogranulomatous pyelonephritis. Differentiation between these tumors and RCC based on pre-operative CT findings was impossible even on retrospective evaluation. 
Table II. Accuracy of pre-operative CT and MR imaging findings according to tumor diameter.

\begin{tabular}{lcc}
\hline & \multicolumn{2}{c}{ Tumor diameter, mm } \\
\cline { 2 - 3 } Variables & $\leq 20$ & $>20$ \\
\hline Total patients, $\mathrm{n}$ & 71 & 125 \\
Pre-operative CT, $\mathrm{n}(\%)$ & & $125(100.0)$ \\
Images obtained & $71(100.0)$ & $121(96.8)$ \\
Accuracy & $62(87.3)$ & \\
Pre-operative MR imaging, n (\%) & & $93(74.4)$ \\
Images obtained & $59(83.1)$ & $92(97.8)$ \\
Accuracy & $50(84.7)$ & $0.0236^{\mathrm{a}}$
\end{tabular}

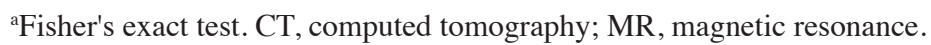
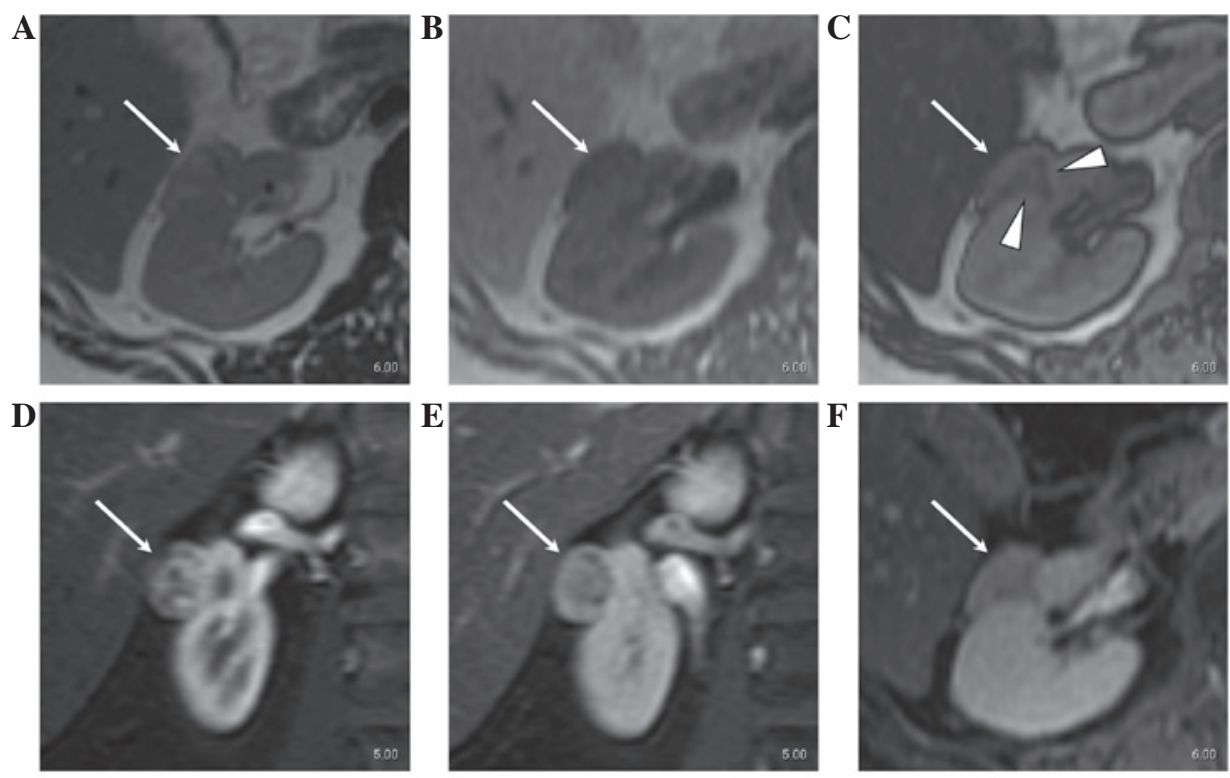

Figure 1. Angiomyolipoma. (A) T2-weighted MR images showed a hyperintense tumor (arrow) protruding from the left renal cortex. Compared with T1-weighted (B) in-phase images, (C) out-phase images showed the tumor exhibiting an area of slight signal loss (arrowheads) indicating microscopic fat. On coronal dynamic images using MR imaging with gadolinium-DTPA, the tumor (arrow) showed marked contrast enhancement in (D) the arterial phase and wash-out of contrast medium in (E) the late phase, indicating renal cell carcinoma. (F) The post-enhanced T1-weighted image also showed hypointensity (arrow). MR, magnetic resonance imaging.

\section{Discussion}

The incidence rates of benign pathological lesions at nephrectomy for presumed small RCC have been reported previously $(5-8,19-23)$. Various incidence rates were reported, and differences were indicated based on ethnicity. The reported incidences of benign pathological lesions with a tumor diameter of $\leq 40 \mathrm{~mm}$ were $17.3-23.4 \%$ in studies from Western countries (5,6,19-22) and 7.1-15.0\% in studies from Asian countries $(7,8,23)$. Fujii et al suggested that one possible reason for the lower incidence of benign pathological findings in Asian than Western countries was the low incidence rate of oncocytoma in Asia (7), which is indistinguishable from RCC using the present imaging modalities (24). The reported incidence rates of oncocytoma in small renal masses were $5.7-10.7 \%$ in Western countries $(5,6,19-22)$ but $1.3-2.8 \%$ in Asian countries $(7,8,23)$, consistent with the results of the present study (1.5\%). Although further studies in various countries are required, these observations suggest that there may be ethnic differences in the oncocytoma incidence rate.

In the present series, the incidence rate of benign pathological lesions for presumed clinical T1a RCC was $6.63 \%$, which was lower than that in previous studies, even considering the low incidence of oncocytoma. The lower incidence of benign pathological findings in the present series may have been due to the high rate $(77.6 \%)$ of pre-operative MR imaging. In previous studies regarding the incidence rate of benign lesions in presumed clinical T1a RCC, the rates of pre-operative MR imaging were low (32\%) (7) or not described $(5,6)$. MR imaging has advantages with regard to detecting small amounts of fat in small renal masses (10-13), which may aid in distinguishing AMLs from RCCs.

With regard to the correlation between the clinical characteristics of the patients and pathological features in surgically 
resected specimens from cases with small renal masses, tumor size appears to be the strongest predictor of malignant pathological features. Previous studies indicated that 12.4-30.0\% of tumors smaller than $2 \mathrm{~cm}$ were benign compared with $4.8-20.9 \%$ of those larger than $2 \mathrm{~cm}$ in cases with small renal masses presumed to be T1a RCC $(5,6,19-23)$. Furthermore, the incidence of benign pathological lesions in the renal tumors of $\leq 20 \mathrm{~mm}$ in diameter was significantly higher (12.7\%) than in tumors $>20 \mathrm{~mm}(3.9 \%)$ in the present series.

The incidence of small benign pathological lesions may depend on the accuracy of pre-operative screening by the radiological approach. A recent study suggested that the accuracy of radiological examination for nodules $<2 \mathrm{~cm}$ in diameter must be improved due to the low incidence of benign lesions in resected suspicious renal masses with diameters $>2 \mathrm{~cm}$ (8). Although there have been no studies regarding the accuracy of pre-operative radiological screening for small renal masses, in the present series, the diagnostic accuracy of pre-operative CT and MR imaging of the renal masses $\leq 20 \mathrm{~mm}$ in diameter were significantly lower than those of the masses $>20 \mathrm{~mm}$ in diameter. Moreover, benign pathological lesions of $\leq 20 \mathrm{~mm}$ in diameter could not be distinguished from RCC in retrospective CT and MR imaging analysis. There may be a limitation of imaging modalities for the pre-operative diagnosis of several small renal masses with diameters of $\leq 20 \mathrm{~mm}$, such as AML without identifiable macroscopic fat on pre-operative imaging (25) and category III renal cysts with the enhancement characteristics of septa on contrast-enhanced CT and MR imaging $(12,18)$.

Analysis of false-negative cases, i.e., pathological T1a RCC clinically diagnosed as benign lesions by pre-operative CT and MR imaging, could not be performed in the present study. This was one of the limitations of this study, and there may have been cases of small RCC missed or followed up as benign disease without pathological diagnosis. There have been few reports regarding such cases, and further challenging issues must be resolved by the development of improved methodologies for percutaneous renal biopsy and molecular pathological analyses (26-28).

In conclusion, in the present study pre-operative CT and MR findings demonstrated high diagnostic accuracy for renal masses $>20 \mathrm{~mm}$ in diameter, however, pre-operative imaging for small renal masses, particularly those of $\leq 20 \mathrm{~mm}$ in diameter, was limited. Therefore, these findings may be useful for the preoperative diagnosis of RCC in clinical practice.

\section{References}

1. Ferlay J, Soerjomataram I, Ervik M, Dikshit R, Eser S, Mathers C Rebelo M, Parkin DM, Forman D and Bray F: GLOBOCAN 2012 v1.0, Cancer Incidence and Mortality Worldwide: IARC Cancer Base No. 11. Available at: http://globocan.iarc.fr. Accessed November 25, 2015.

2. Laguna MP, Algaba F, Cadeddu J, Clayman R, Gill I, Gueglio G, Hohenfellner M, Joyce A, Landman J, Lee B and van Poppel H; Clinical Research Office of the Endourological Society Renal Mass Study: Current patterns of presentation and treatment of renal masses: A clinical research office of the endourological society prospective study. J Endourol 28: 861-870, 2014

3. King SC, Pollack LA, Li J, King JB and Master VA: Continued increase in incidence of renal cell carcinoma, especially in young patients and high grade disease: United States 2001 to 2010. J Urol 191: 1665-1670, 2014.
4. Chang X, Liu T, Zhang F, Ji C, Zhao X, Wang W and Guo H: Radiofrequency ablation versus partial nephrectomy for clinical T1a renal-cell carcinoma: Long-term clinical and oncologic outcomes based on a propensity score analysis. J Endourol 29: 518-525, 2015.

5. Remzi M, Özsoy M, Klingler HC, Susani M, Waldert M, Seitz C, Schmidbauer J and Marberger M: Are small renal tumors harmless? Analysis of histopathological features according to tumors $4 \mathrm{~cm}$ or less in diameter. J Urol 176: 896-899, 2006.

6. Pahernik S, Ziegler S, Roos F, Melchior SW and Thüroff JW: Small renal tumors: Correlation of clinical and pathological features with tumor size. J Urol 178: 414-417, discussion 416-417, 2007.

7. Fujii Y, Komai Y, Saito K, Iimura Y, Yonese J, Kawakami S, Ishikawa Y, Kumagai J, Kihara K and Fukui I: Incidence of benign pathologic lesions at partial nephrectomy for presumed RCC renal masses: Japanese dual-center experience with 176 consecutive patients. Urology 72: 598-602, 2008.

8. Soga N, Nishikawa K, Takaki H, Yamada Y, Arima K, Hayashi N and Sugimura Y: Low incidence of benign lesions in resected suspicious renal masses greater than $2 \mathrm{~cm}$ : Single-center experience from Japan. Int J Urol 19: 729-734, 2012.

9. Sheth S, Scatarige JC, Horton KM, Corl FM and Fishman EK: Current concepts in the diagnosis and management of renal cell carcinoma: Role of multidetector ct and three-dimensional CT. Radiographics 21 (suppl_1): S237-S254, 2001.

10. Hecht EM, Israel GM, Krinsky GA, Hahn WY, Kim DC, Belitskaya-Levy I and Lee VS: Renal masses: Quantitative analysis of enhancement with signal intensity measurements versus qualitative analysis of enhancement with image subtraction for diagnosing malignancy at MR imaging. Radiology 232: 373-378, 2004.

11. Ho VB, Allen SF, Hood MN and Choyke PL: Renal masses: Quantitative assessment of enhancement with dynamic MR imaging. Radiology 224: 695-700, 2002.

12. Israel GM, Hindman N and Bosniak MA: Evaluation of cystic renal masses: Comparison of CT and MR imaging by using the Bosniak classification system. Radiology 231: 365-371, 2004.

13. Silverman SG, Mortele KJ, Tuncali K, Jinzaki M and Cibas ES: Hyperattenuating renal masses: Etiologies, pathogenesis, and imaging evaluation. Radiographics 27: 1131-1143, 2007.

14. Furman SA, Lasky LC and Limas C: Prognostic significance of morphologic parameters in renal cell carcinoma. AM J Surg Pathol 6: 655-663, 1982.

15. Kovacs G, Akhtar M, Beckwith BJ, Bugert P, Cooper CS, Delahunt B, Eble JN, Fleming S, Ljungberg B, Medeiros LJ, et al: The Heidelberg classification of renal cell tumours. J Pathol 183: 131-133, 1997.

16. Greene FL, Page DL, Fleming ID, Fritz AG, Balch CM, Haller DG and Morrow M (eds): AJCC Cancer Staging Manual. 6th edition. Springer Science and Business Media, New York, NY, 2002.

17. Kitagawa Y, Nakashima K, Shima T, Izumi K, Narimoto K, Miwa S, Miyagi T, Maeda Y, Kadono Y, Konaka H, et al: Clinicopathological outcomes of clinical T1a renal cell carcinoma by tumor size. Jpn J Clin Oncol 41: 637-641, 2011.

18. Israel GM and Bosniak MA: An update of the Bosniak renal cyst classification system. Urology 66: 484-488, 2005.

19. Snyder ME, Bach A, Kattan MW, Raj GV, Reuter VE and Russo P: Incidence of benign lesions for clinically localized renal masses smaller than $7 \mathrm{~cm}$ in radiological diameter: Influence of sex. J Urol 176: 2391-2395, discussion 2395-2396, 2006.

20. Duchene DA, Lotan Y, Cadeddu JA, Sagalowsky AI and Koeneman KS: Histopathology of surgically managed renal tumors: Analysis of a contemporary series. Urology 62: 827-830, 2003.

21. Schlomer B, Figenshau RS, Yan Y, Venkatesh R and Bhayani SB: Pathological features of renal neoplasms classified by size and symptomatology. J Urol 176: 1317-1320, discussion 1320, 2006.

22. Frank I, Blute ML, Cheville JC, Lohse CM, Weaver AL and Zincke H: Solid renal tumors: An analysis of pathological features related to tumor size. J Urol 170: 2217-2220, 2003.

23. Xiong YH, Zhang ZL, Li YH, Liu ZW, Hou GL, Liu Q, Yun JP, Zhang XQ and Zhou FJ: Benign pathological findings in 303 Chinese patients undergoing surgery for presumed localized renal cell carcinoma. Int J Urol 17: 517-521, 2010. 
24. Marhuenda A, Martín MI, Deltoro C, Santos J and Rubio Briones J: Radiologic evaluation of small renal masses (I): Pretreatment management. Adv Urol 415848: 415848, 2008.

25. Prasad SR, Surabhi VR, Menias CO, Raut AA and Chintapalli KN: Benign renal neoplasms in adults: Cross-sectional imaging findings. AJR Am J Roentgenol 190: 158-164, 2008.

26. Lane BR, Samplaski MK, Herts BR, Zhou M, Novick AC and Campbell SC: Renal mass biopsy - a renaissance? J Urol 179: 20-27, 2008.
27. Volpe A, Kachura JR, Geddie WR, Evans AJ, Gharajeh A, Saravanan A and Jewett MA: Techniques, safety and accuracy of sampling of renal tumors by fine needle aspiration and core biopsy. J Urol 178: 379-386, 2007.

28. Izumi K, Narimoto K, Sugimoto K, Kobori Y, Maeda Y, Mizokami A, Koh E, Yamada T, Yano S and Namiki M: The role of percutaneous needle biopsy in differentiation of renal tumors. Jpn J Clin Oncol 40: 1081-1086, 2010. 